\title{
THE SUB-DEPARTMENT OF ANIMAL BEHAVIOUR, UNIVERSITY OF CAMBRIDGE
}

\begin{abstract}
I 1950, the Cambridge University Department of Zoology established an Ornithological Field Station at Madingley, about four miles from the centre of the City. The object of this was to provide aviary and other facilities for the investigation of bird behaviour, with special reference to the relative influence of two factors affecting the development of behaviour in the individual. These two factors are, on one hand, the innate disposition of the animal-in broad general terms, its 'instincts'- and on the other its ability to profit by experience, that is to say, the degree to which it can display the various types and degrees of learning. Birds are of particular interest from this point of view in that they combine high learning ability with elaborate instinctive bohaviour patterns to an extent which is probably unique in the animal kingdom. The Field Station was from the first under my general direction, with Dr. R. A. Hinde as curator. As the work developed, experiments were extended to a number of species of mammals in addition to birds and the title was changed to the Field Station for the Study of Animal Behaviour. In 1960, the University established a Sub-department of Animal Behaviour as part of the Department of Zoology, with me as director and Dr. Hinde as assistant director of research. It was envisaged that there would ultimately be 8-10 other workers. Of these, three or four would be rather senior, holding relatively long-term research grants or appointments
\end{abstract}

-the total scientific strength of the Station being completed by research students and senior visiting workers from other universities. In addition, there would, of course, be an appropriate technical staff.

This development, and the experience of a number of years, made clear the necessity for a permanent building in addition to the temporary accommodation which had sufficed hitherto. The earlier stages of development of the Field Station had been made possible by generous help from various sources, particularly the Nuffield Foundation and the Josiah Macy Foundation of Now York. When the more extensive needs became known, the former again came most generously to our aid and gave the University a grant of $£ 50,000$, of which $£ 30,000$ was to be allocated to the immediate capital needs and the remaining $£ 20,000$ to be devoted to the current expenditure over a period not exceeding seven years. The Rockefeller Foundation generously followed this up with a grant of $£ 23,330$ of which $£ 5,830$ is to be used for the purchase of scientific equipment and $£ 17,500$ for more general expenses of research over a five-year period.

The site consists of about $4 \frac{1}{2}$ acres of field and woodland, the whole fenced with vermin-proof fencing. Within this area are outdoor pens and enclosures, a monkey house for the accommodation of four groups of seven or eight monkeys, each with extensive indoor and outdoor quarters. Madingley Wood

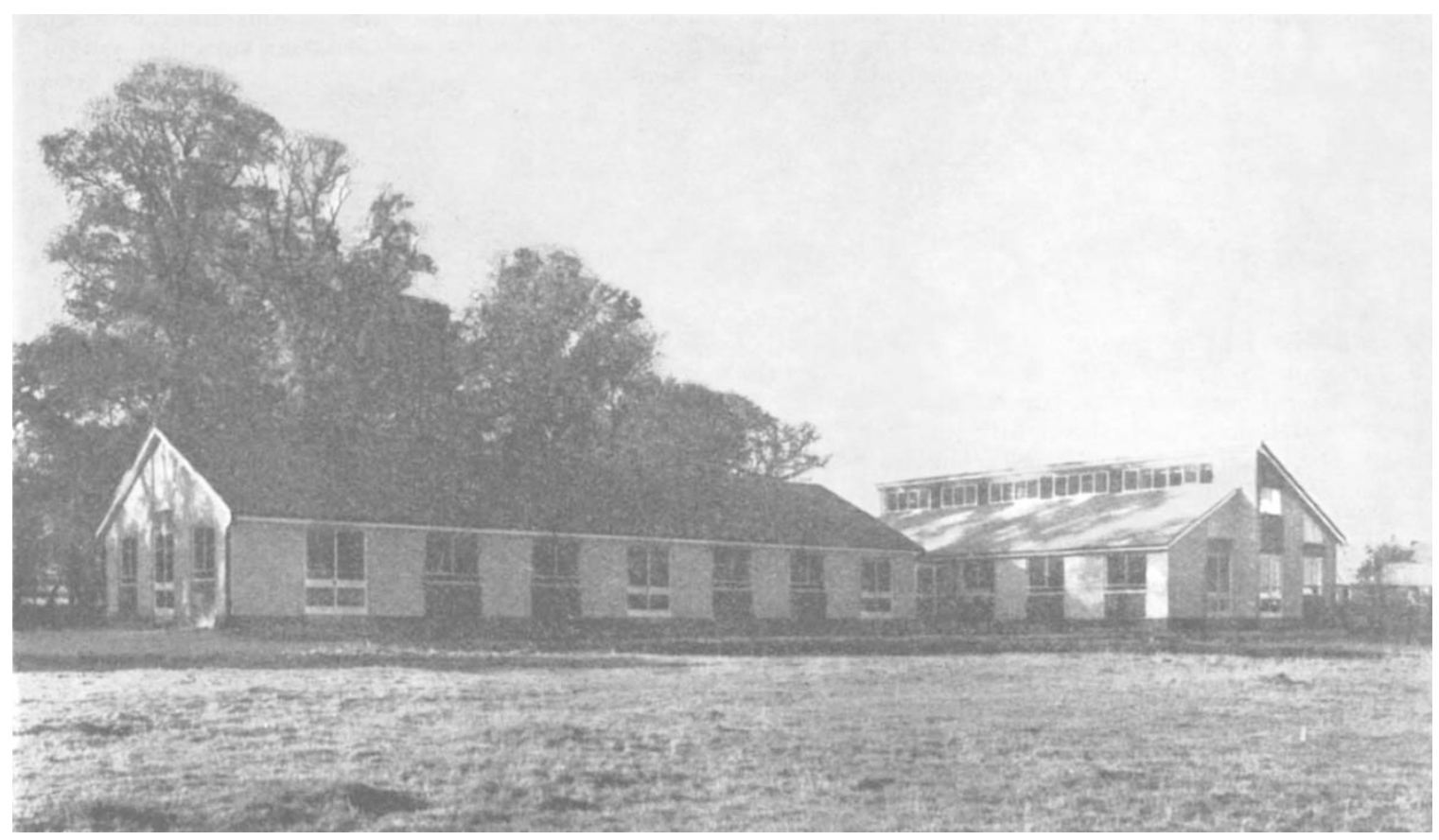

Fig. 1. The Sub-department of Animal Behaviour, University of Cambridge 
(38 acres), which is a biological preserve of the University, and the lake in Madingley Park are also available for certain research projects. There are 60 small and 12 large aviaries and a large number of indoor bird-rooms and flights, as well as two sound-proof rooms especially constructed for the isolation of experimental birds from those frequencies which constitute the essential basis of bird songs and call notes. An admirable building (Fig. 1), designed by Mr. Peter Bicknell, of Messrs. Hughes and Bicknell, Cambridge, has now been erected and the Subdepartment occupied it in August 1962. The new building is divided into approximately twelve individual research rooms, dark room, histology room, office, accommodation for full equipment of soundproof cages, garage, workshop, etc. There are also three large rooms, one of which is at present being used as an isolation room for primates and birds, while the others accommodate small mammals and fish. The roofs are pitched, and the whole of the roof space is utilized. In one block the two roof slopes are split at the ridge to give a continuous clerestory, lighting small workrooms. In the other block there is a continuous loft $80 \mathrm{ft} . \times 30 \mathrm{ft}$. uninterrupted by roof timbers, which can be used for experiments requiring a long indoor runway or large choice chambers. There is also a house for the senior assistant in charge.

It is intended that the first main line of investigation of workers in the Sub-department should continue to be the instinct/learning problem, particularly as exemplified in the study of sensitive periods in learning. Such a heading includes several lines of work which the experience of the past few years has shown to be the most promising. With birds it would include studies on the ontogeny of new motor actions, and the continuance of studies on song-learning and vocal imitation and their sensory and motor control. Studies on the ontogeny of species-characteristic behaviour, particularly work such as that on the analysis of the role of experience in nest-building, will be continued. Studies on mammals will, as hitherto, centre round the mother-offspring relation, and the work with the now well-established colony of rhesus monkeys is proceeding. The second main field of investigation can broadly be described as 'motivation'. This, of course, interdigitates with the first - for example in the analysis of song patterns, endocrinology (particularly of nest-building) and studies of changes in responsiveness to a constant stimulus.

The third main aspect of the work can broadly be called physiology. Studies on the hormonal control of the cycle of reproductive behaviour, especially of nest-building in canaries, has already been mentioned, but a new development is the initiation of neurophysiological investigations. While much is known about the neurophysiological changes concerned with learning in mammals, the neurophysiological understanding of the essential mechanisms involved in what are generally known as 'instinctive actions' is, by comparison, meagre in the extreme. When we come to birds, in which these instinctive actions are far more obvious and highly developed than they are in the mammals, neurophysiological information is almost non-existent. The application of new techniques of central stimulation seem to offer great promise in this field.

In the past, workers in the Sub-department have been fortunate in being able to maintain close contact with colleagues in related. fields. Thus we have had elose co-operation with members of the Department of Experimental Psychology, under Prof. O. Zangwill, and especially with the workers on primates thereDr. L. Weiskrantz and his associates. Also within the University, contact has been maintained with the Department of Physiology (Sir Bryan Matthews), and we look forward to future collaboration with the new Department of the Physiology of Reproduction under Prof. A. S. Parkes. Outside Cambridge, we have worked closely with Dr. John Bowlby of the Tavistock Clinic, who is investigating mother/infant interaction in man. We hope that such co-operation will be increased and extended as a result of the new developments because we believe that ethology has a special part to play in the establishment of mutually profitable relations between the various behavioural sciences.
W. H. THORPE

\section{PROBLEMS OF COMMUNICATING SCIENTIFIC IDEAS}

\begin{abstract}
A TENTATIVE Study of the Publication of $A$ Original Scientific Literature*, issued by the Abstracting Board of the International Council of Scientific Unions, like the study of The Foreign Language Barrier in Science and Technology $\dagger$, recently published by Aslib, is concerned with the availability of original publications in foreign languages. Both are based on fresh surveys, but, except in respect of courses in Russian for scientists, neither adds substantially to the findings of the report, Scientific and Technical Translating and other Aspects of the Language Problem, issued in 1957 by the United Nations Educational, Scientific and Cultural Organization

* Conseil International des Unions Scientifiques, Paris. Bureau des Resumes Analytiques. A Tentative Study of the Publication of Original Scientific Iiterature. Pp. 11 + 16 tables. (Paris: Conseil International des Unions Scientifiques, 292 rue Saint-Martin, 1962.)

$\dagger$ The Foreign Language Barrier in Science and Technology. (A study based upon three investigations carried out in the Research 128 .
\end{abstract}

(see Nature, 180, 1170; 1957). However, the Aslib report refers to this earlier and much more comprehensive report. The report from the International Council of Scientific Unions is based on a questionnaire sent early in 1960 to 260 selected periodicals, mainly in Europe, but 86 did not reply. The survey did not pretend to give a representative sampling of original publications, but in view of the fact that a sampling of 1,000 periodicals for the Unesco survey indicated that some 61.5 per cent of the papers were in English and only 17.4 per cent in French and $\mathbf{2 \cdot 2}$ per cent in German, the selection of 72 French periodicals and 33 German compared with 39 British and 63 United States seems to rob the findings of some substance. Russian periodicals, which in the Unesco survey accounted for some 10 per cent, were not included, though this language was in 1957 competing for the second place, and Japanese was then challenging French for fifth. 